\title{
Sustainability as Cognitive "Friction": A Narrative Approach to Understand the Moral Dissonance of Sustainability and Harmonization Strategies
}

\author{
Franzisca Weder ${ }^{1 *}$, Amornpan Tungarat ${ }^{2}$ and Stella Lemke ${ }^{3}$ \\ ${ }^{1}$ School of Communication and Arts, University of Queensland, Brisbane, QLD, Australia, ${ }^{2}$ Department of Media and \\ Communication Studies, University of Klagenfurt, Klagenfurt, Austria, ${ }^{3}$ Institute for Social Medicine and Epidemiology, \\ University of Lübeck, Lübeck, Germany
}

\section{OPEN ACCESS}

Edited by:

Anabela Carvalho,

University of Minho, Portugal

Reviewed by:

Nick C. Nash

Cardiff University, United Kingdom

Ana Delicado,

Institute of Social Sciences, University

of Lisbon, Portugal

*Correspondence:

Franzisca Weder

franzisca.weder@gmail.com

Specialty section:

This article was submitted to Science and Environmental

Communication

a section of the journal Frontiers in Communication

Received: 23 October 2019 Accepted: 31 January 2020

Published: 21 February 2020

Citation:

Weder $F$, Tungarat $A$ and Lemke $S$ (2020) Sustainability as Cognitive

"Friction": A Narrative Approach to

Understand the Moral Dissonance of

Sustainability and Harmonization

Strategies. Front. Commun. 5:8

doi: 10.3389/fcomm.2020.00008
Narratives represent storied ways of knowing and communicating, thus, have always been a key feature in media and communication research. In our contribution, a concept to explain sustainability-related cognitive dissonances as well as a new version of a narrative inquiry is introduced to capture reflections on experiences of sustainability and individual assessments of (un)sustainable behavior over time. We perceive storytelling as an action, as act of problematization which uncovers cognitive dissonances and coping strategies. Using Rory's Story Cubes ${ }^{\circledR}$ (dice with pictograms), we stimulated 35 interviewees from various cultural backgrounds (Asian, European, Anglo-American) to "story" sustainability-related life events into order and meaning. Our evaluation of the interviews ${ }^{1}$ focused on the story as a whole, which was then linked to the individual biographical background to understand motives for and moral conflicts about (un)sustainable behavior. In the paper we discuss and critique this theoretical concept and the related innovative inquiry form in the area of environmental communication research to gain a better understanding of individual perceptions of sustainability, moral dissonances, and cognitive friction occurring in relation to sustainability-related issues.

Keywords: sustainability communication, cognitive dissonance, cognitive friction, storytelling, narrative interviews, triangulation

\section{INTRODUCTION}

Over the last two decades, the idea of sustainability has gained traction, mainly in political and corporate discourses. Sustainability, per se, can be defined as the fact that a given activity is capable of being sustained and therefore, continued (Johnston et al., 2007, p. 61), enabling the co-existance of human and nature, creating an ecocultural identity and generate restorative alternatives and transformation. Today, sustainability is frequently used as an important goal set by governments, NGOs and businesses, as well as trans-national organizations such as the United Nations, which developed the 17 Sustainable Development Goals. These goals are now part of the 2030 Agenda entitled "Transforming our world: the 2030 Agenda for Sustainable Development" (United Nations, 2018). There, sustainable development is characterized as a societal process of learning and

\footnotetext{
${ }^{1}$ Consent to the publication of their verbatim quotes was obtained from all the participants.
} 
creation. There is a common sense-at least in western countries - that the idea of sustainability has to be negotiated in public deliberation (Weder, 2017; Kuntsman and Rattle, 2019). Based on this idea, there is a consensus that sustainable development includes normative ideas: responsibility for the future, meeting global needs, protection of the environment, development as a deeper logic and matter of life, integration of economy and environmental responsibility, as well as participation and engagement. Thus, the conceptualization of the ideas and ways of their realization is a matter of contestation, or from a critical, constructivist perspective: a matter of deliberation and sense-making processes. The complex and unsettled nature of sustainability is seen by some as a limitation on acknowledging the idea in practice and even on efforts to achieve meaningful sustainability (Marshall and Toffel, 2005, p. 30-32). Sustainability is described as "wicked problem" (Herrick and Pratt, 2013, p. $4,434)$; therefore, we can state that communication plays a crucial role for a sustainable development.

A debate about the narratives and meaning of sustainability and their origin has been raised in the academic outlets, professional media, and public debates lately. Here, sustainability is described as a highly contested term and often labeled as an "empty" word (King, 2013) or a concept where discourses on different levels have managed to overextend its meaning "to the point of trivialization" (Ott et al., 2011, p. 13), mainly because the terms are blurry, fuzzy and ambiguous (Krainer and Weder, 2011; Fischer et al., 2017). In the public sphere, the concept of sustainability is often associated with environmental issues such as climate change and global warming; with social issues such as poverty, water scarcity and social inequalities; and with business economic issues such as resource insufficiency and sustainable agriculture. As often as it is discussed in different discourses and public deliberation processes, a discernible definition of the word has rarely been discussed and analyzed. Giovannoni and Fabietti (2013) suggested that the reason for this is, that the term has a multidimensional (environmental, social and business) and integrated definition, which creates tension between the different dimensions.

The lack of consensus between science, politics, business sphere, related public discourses, and the media is generating uncertainties for individuals, causing emotional, and cognitive detachment from the concept itself and hindering appropriate practices that would respond to the risk of unsustainable living. This leads to cognitive dissonance within an individual's mind. Cognitive dissonance theory (Festinger, 1962) states that when human beings have conflicting ideas in their minds, they would try to unify the ideas, as dissonance is a naturally uncomfortable state of mind. In the case of sustainability, the conflict would be acting sustainably, this could require effort, cause inconvenience, and conflict. Therefore, it is also human to reduce that dissonance through one of three strategies (Festinger, 1962): change in behavior; change in belief; or justifying the behavior. In our paper, we outline an innovative conceptual and methodological approach to better understand sustainability communication on an individual level. Therefore, we conceptualize sustainability as normative framework (Hoppe and Wolling, 2017), as a normative claim for a specific action (or inaction, i.e., not flying).
This type of framework not only influences individual decisionmaking processes (such as consumption, mobility), but also influences the wider arguments, narratives, and frames that are used to account for or justify a specific action (or inaction) related to sustainability as normative framework.

Based on an innovative storytelling approach supported with "Story Cubes" used in narrative inquiries, entirely developed within our research lab (Weder et al., 2019a), we are able to focus on the problematization of events and actions evaluated as (un)sustainable. With this, it is possible to learn about the normative character of sustainability as framework influencing individual behavior as well as individual strategies to use "sustainability communication" for the interpretation of their individual behavior.

In the following chapters, the research gap of sustainability communication on an individual level is identified and a new theoretical concept and related methodology is introduced as "restorying sustainability" (Weder et al., 2019a). After explaining the innovative methodological approach, the findings of the narrative interviews are presented and discussed with a specific focus on cognitive dissonances and cognitive friction emerging in the process of storytelling. In addition, the limitations of the study are reflected and an outlook on the academic contribution of this project toward environmental and sustainability communication research is given.

\section{LITERATURE REVIEW}

The state of art in sustainability communication is, that there are only a few bits of literature offering an overview in this area (Brackin et al., 2011; Godemann and Michelsen, 2011; Dade and Hassenzahl, 2013; Allen, 2016). They show, that sustainability studies and other scientific engagement with the notion of sustainable development has an interdisciplinary, as well as transdisciplinary character (Weder et al., 2019b). There is a common ground of understanding sustainability communication as "introducing an understanding of the world, that is of the relationship between humans and their environment, into social discourse" (Godemann and Michelsen, 2011, p. 6). However, there is a lack of a broader, cultural perspective on sustainability communication; most of the literature approaches either communication about sustainability or communication for sustainable development (Newig et al., 2013; Genc, 2017). In both dimensions, the functional, instrumental understanding of communication dominates and is increasingly explained and explored (Bjorn et al., 2019; Kuntsman and Rattle, 2019) with a focus on sustainability reporting, social impact (Daily and Huang, 2001; McKenzie, 2004; Chaudhuri and Jayarem, 2018), specific media to communicate sustainability (Huang et al., 2019; Maltseva et al., 2019) or dissemination strategies and pedagogical approaches (van Dam-Mieras et al., 2008; Djordjevic and Cotton, 2011; Sprain and Timpson, 2012; Genc, 2017). Furthermore, there is a link to the established fields of corporate social responsibility (CSR) communication (Elving et al., 2015; Diehl et al., 2017; Golob et al., 2017; Rasche et al., 2017; Weder et al., 2019b), climate change communication (Stecula and Merkley, 
2019) and sustainable consumption communication (Bilharz and Schmitt, 2011; Linea et al., 2016).

The research gap concerning a broader perspective on all communication processes where information, interpretations, values and opinions regarding sustainability issues are influencing cognitive processes seems worth a further exploration. Thus, in our contribution, we will take a broader perspective, not only on the sustainability-related information itself, but also the way it is interpreted and imbued with values and aligned with opinions, influences individual cognitive processes in complex ways. With this paper, we add another aspect to communication about and for sustainability. Coming from a cultural, social constructivist perspective, sustainable communication in terms of communicatively constructed morality, which is represented in individual sense-making processes needs more scholarly attention.

As mentioned above, sustainability issues are characterized by high levels of complexity and uncertainty (Genc, 2017, p. 514) and a mutual understanding between various communicators, bridging the expert lay gap in particular (Bäckstrand, 2003). But what are the principles and techniques that promote and govern processes of deliberation that individuals, as well as collectives, use to understand complex systems so that they can make informed decisions while confronting multiple, and sometimes, conflicting objectives (Stern, 2005)? Recommendations are deliberations on available scientific data and information, transparency of processes and value orientation and interest (Herrick and Pratt, 2013). With a cultural approach, sensemaking processes happen on an individual level as "intellectual refinement associated with arts, philosophy and learning" (du Gay et al., 1997, p. 11); sustainability is part of culture today through which we all understand and interprete the world (Weder, 2017).

László (2008) pointed out that people create stories in order to better understand the world and they share the stories with others. Hence, narratives are seen as a public carrier of human experience and framing of their environment. A narrative is "the organizing principle of how people give sense of the world" (László, 2008, p. 103). Embedded in a social constructivist perspective with a narrative approach, we are able to understand individual lives, social representations and interpretations. Furthermore, a narrative can act as both, as a means to construct social representations and as the framework to study them (Laszlo, 1997; Weder et al., 2019c, p. 164).

Methodologies that capture situations and contexts for individual sense-making processes follow a constitutive view on communication and acknowledge the social-constructivist aspects of conversations and narrations. Thus, in our contribution, we draw on narratives as not only a mode of knowing, but much more a process through which knowledge is constructed and sense is made. A narrative (or story) has a structure that usually focuses on two aspects, the sequence of events and the actions of one single or more characters (Dahlstrom and Ho, 2012; De Graaf et al., 2016). In addition, stories as narratives are characterized by some kind of problem or conflict (here: dissonance, which will be conceptualized in the next sub-chapter) as well as a cause-and-effect-structure
(Hinyard and Kreuter, 2007; Dahlstrom, 2014). This conflict includes a stimulative problematization and moral judgementsrelated to a specific normative framework. Eckstein (2003) and Sandercock (2003) explain this sense-making that comes along with narratives when each individual has a core story and that they become their stories by telling and re-telling them and "reproducing" themselves.

Our specific perspective on individual sustainability communication then has to embrace the "production and exchange of meanings (giving and taking of meanings) between the members of a society or group" (Hall, 1997, p. 2), as well as the interlocked behaviors (Weick, 1979) and events of communication as constitutive (Taylor and Van Every, 2000). Therefore, we believe that a cultural perspective offers a better understanding of contradictions and the degree of morality in sustainability communication from an individual perspective as constitutive and cognitive dissonances related to the inconvenient truths coming along with sustainability as normative framework and following moral uncertainties, which will be further elaborated in the next section.

\section{FROM DISSONANCE TO HARMONIZATION}

Focusing on the individual's perception of sustainability, and their understanding of related-complex-normative frameworks influencing their social practices, we have to acknowledge multiple and sometimes conflicting objectives that individuals are confronted with (Stern, 2005; Herrick and Pratt, 2013) as well as cultural factors that are related to and influence a specific behavior. Sustainability is a complex issue and individuals are bombarded with an abundance of information regarding it; it is the culture as well as the cultural identity of an individual which decides the way of behavior-as well as the evaluation of this behavior. A "sustainable identity" is defined as feature of self-perception and cognition in relation to a cultural context and information that drives and/or motivates (eco)cultural action (Stibbe, 2015). Related to climate change and sustainability, the increasingly large amount of information challenges identity-building processes, which is called "complex cognition" (Knauff and Wolf, 2010), which can be further defined from two perspectives: complex psychological processes and complex conditions, like information overload (Edmunds and Morris, 2000). In the aspect of complex psychological processes, "complex cognition" refers to mental activities such as decision-making, problem-solving that links to cognitive processes such as perception and working memory, as well as emotion and motivation. All of the above creates complex cognition in a psychological process perspective. Thus, when speaking of climate protection, sustainable behavior related to a specific cultural context, various actors must be taken into account, such as ecological, geological, economical, and political factors. These factors are at a constant change and the relevance of information as well as counter-measures are not clear. Thus, the complex nature of climate change and other relevant complexities in interpreting information can lead to 
manipulative and self-deceptive behavior, which influences the degree to which individuals are motivated to attend to or discount different types of information.

Therefore, when it comes to behaving sustainably, individuals can manifest a self-deceptive behavior and specify which sustainable actions to perform, which could cause dissonance. Here, we go with Aronson (1969, p. 20) who linked and compared the dissonance theory with the reward-incentive theory. This means that although advocates of the dissonance theory would not oppose the fact that individuals would be more prone to carry out and repeat actions that would gain them rewards, they would say that "under certain carefully prescribed conditions" (Aronson, 1969) individuals would have an alternate behavior than with the reward-incentive theory. According to the aforementioned theories, people will behave sustainably if they receive an incentive, which in this case could be a self-deceptive illusion of "doing a good thing" - related to a further established normative framework for sustainable behavior. This imitation of a self-deceptive reward is one of the strategies to cope with cognitive dissonance appearing when the behavior is evaluated as "un-sustainable."

The term cognitive dissonance itself was coined by Festinger (1962), which investigated the nature of the human psyche regarding conflicting ideas and behavior. The author said that when human beings come across an issue, which creates conflicting ideas in their minds, they would try to coordinate those conflicting ideas-or dissonance-because being in such a state is naturally uncomfortable. An example of an everydaydissonance related to sustainability which could happen to anyone is eating fast food. An average person knows that eating fast food is not beneficial to their health and harms the environment (Woods, 2010). However, it cannot be denied that people still do it. Deciding to go through with an action, fully aware of its "bad" effects or qualities of individual life as well as on a larger (global) scale, creates dissonance inside the person's mind. According to Festinger (1962), there are three methods that people use to reduce the aforementioned dissonance, namely changing behavior, changing belief, and rationalizing or justifying the action. From the example given before, the person dealing with cognitive dissonance regarding eating fast food would have to change their behavior i.e., stop eating fast food, change their belief i.e., disregard any information or studies about disadvantages of fast food or to justify their behavior i.e., tell themselves that they will eat a salad as their next meal to compensate for their "bad" decision.

After the publication of theory, Festinger's cognitive dissonance research influenced the field of social psychology (Harmon-Jones and Harmon-Jones, 2007, p. 7). However, it was not done without being questioned. One of the most famous alternative theories to cognitive dissonance is Bem's (1967) self-perception theory, followed by Steele's (1988) argument of reduced dissonance through maintaining a positive self-image. Bem suggested that attitude change does not come from the discomfort of dissonance but rather through the act of observing one's own behavior. With that being said, investigated both theories and came to the conclusion that both ".... are not capable of producing unequivocally contradictory predictions of cognitive consequences of experimental procedures". Sustainability as a global framework with several implications for individuals needs a concept that embraces cultural and societal value as well.

Five decades after the original publication of Festinger's theory, Lowell (2012) accommodates Festinger's cognitive dissonance theory with the explicit notion of morality. He added the morality component through one simple question: will the action harm someone else? Therefore, it differs from Festinger's model- "good" or "bad" to "right" or "wrong." The author stated that to reduce moral dissonance, a person goes through an external justification. In order for a person to justify a specific practice like a short-distance flight or fast-food eating behavior without moral guilt, or in other words reduce their moral dissonance, is to create a story that would eliminate that guilt e.g., my job forced me to fly, therefore, I do not need to feel guilty about flying.

Gardiner (2013, p. 301-321) came up with a similar model, with an even stronger focus on the broader moral framework dealing with environmental issues, specifically climate change. The author described moral corruption as "(a) a tendency to rationalize, which (b) casts doubt on the validity and/or strictness of moral claims, by (c) seeking to pervert their status and substance, and in doing so (d) aims to make those claims better suited to our wishes and inclinations, and (e) destroys the characteristics in virtue of which we respect them" (Gardiner, 2013, p. 307). Simply put, moral corruption happens when people justify their immoral behavior by seeing it as weak or less strict and changing the morality of their behavior to coincide with their beliefs: moral corruption is invited in the form of denial mechanisms. These can be found in the literature, namely as distraction and procrastination, complacency, unreasonable doubt, selective attention, delusion, pandering, cynicism, and hypocrisy (Lever-Tracy, 2010; Norgaard, 2011; Dunlap, 2013; Ziegler et al., 2014, p. 1021). As well, this concept is related to the process of moral licensing, discussed mainly in consumer behavior research (Merritt et al., 2010; Blanken et al., 2015).

In the context of sustainability, we offer a new model to understand coping strategies with cognitive and moral dissonance related to sustainability as moral framework: Sustainability Dissonance Harmonization (SDH) combines Festinger's (1962), Lowell's (2012), and Gardiner's (2013, p. 307) ideas using different aspects of each model to acclimatize it to the notion of sustainability, as seen in Figure 1.

The SDH model derived from Festinger's (1962) cognitive dissonance model, through the idea that two conflicting ideas must be harmonized, as well as the two coping strategies, namely belief adjustment and behavioral justification. Furthermore, using Lowell's (2012) moral dissonance model, conducting unsustainable actions would harm others in the long run, which, according to the model demonstrates that unsustainable actions could be seen as immoral behaviors. Finally, Gardiner's (2013, p. 301-321) justification inclination toward the individual's own beliefs from the moral corruption model was included in the SDH model. Simply put, sustainability dissonance harmonization suggests that when it comes to sustainabilityrelated internal dissonance, which would occur by doing 


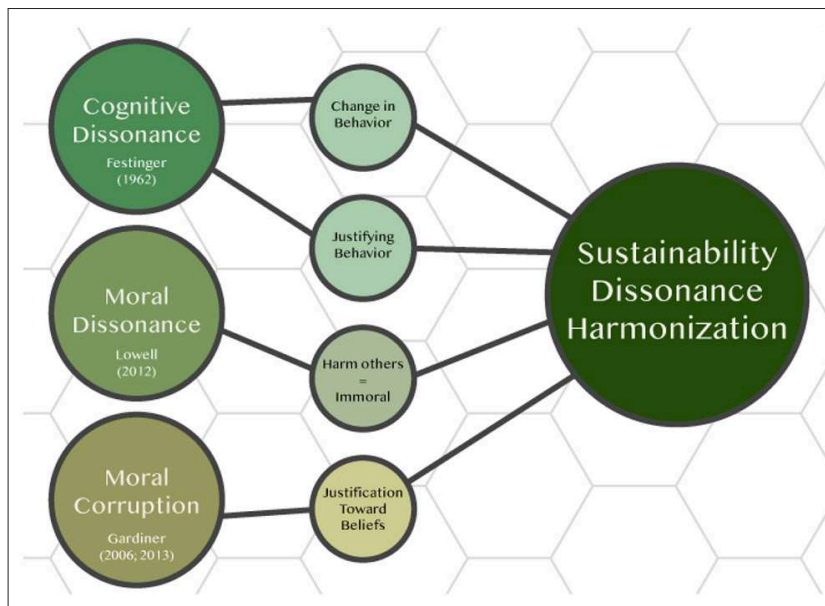

FIGURE 1 | The derivation of sustainability dissonance harmonization (SDH), model.

unsustainable actions, individuals will try to harmonize their conflicting thoughts by justifying their immoral (unsustainable) behavior using logic which is inclined toward convenience in their lifestyle. With the complementary model it can be expressed that dissonance and related strategies to reduce it are related to the certain complexity of an issue. Thus, we can show, that sustainability as normative framework does not only influence individual behavior with its certain degree of morality; much more, confronted with it, individuals try to deconstruct sustainability to make it applicable in their behavior or cope with dissonance appearing with unsustainable behavior. Related to the model, an innovative approach is necessary to analyse the dissonances and harmonization strategies, developed in the research lab "re-storying sustainability" (Weder et al., 2019a) and explained in the following chapter.

\section{METHODOLOGICAL FRAMEWORK}

As introduced at the beginning of this paper, we focus on problematization as social practice, that is seen as core process of storytelling. Sustainability as complex issue challenges indivuals in their "re-telling" and "reproduction"-processes, further conceptualized as communicative strategy to (at the end) "harmonize" dissonant practices. Problematization as process includes a constructive and deconstructive perspective, starting with the recognition of a situation or idea as problematic and an increasing level of involvement (Crable and Vibbert, 1985). Here, from a practical perspective, problematization is approached as process of critical (ethical) reflection which implies the demythicization of common knowledge or common sense issues like sustainability (Weder, 2017) and, thus, implies a deconstruction of a situation that has so far been taken for granted. At the same time, problematization is constructive, it offers new viewpoints, consciousness, hope, and action to emerge (Crotty, 1998).
Thus, to analyze what individuals problematize and to grasp the process of construction and deconstruction by the same time, a narrative approach will be methodologically enriched by problematization as focus of our analysis by asking how and why a phenomenon, a certain process or social practice and/or individual behavior is seen as problem(atic) to challenge insights in coping-here: harmonization-strategies. This challenge leads to an innovative way to let people tell stories and work with their stories as material for understanding the individual perception, problematization, and harmonization of sustainability-related dissonances.

As a framework for narrative interviews, the storytelling approach involves life story research or oral history using semistructured interviews. The qualitative framework for "re-storying sustainability" developed by Weder et al. (2019a), bases on thematic analyses (e.g., Braun and Clarke, 2006), grounded theory approaches (e.g., Charmaz, 2014) and the so called "Interpretive Phenomenological Analysis" (e.g., Smith et al., 2009). The stories show the experience that is made through events which rise in action (Frank, 2017, p. 312) and have a so-called turning point that leads to a resolution (Miller, 1995; Aristotle, 1996; Bal, 1997; Gass, 2002). Just recently, the first attempts to study narratives of sustainability are published and stories of sustainability or storied versions of conceptual frameworks of sustainability (Frank, 2017). The author explains, based on Lyotard (1984) and Polkinghorne (1988) that the narrative as a mode of knowing is concrete, contextualized, specific, and personally convincing as well as imaginistic, interpersonal and emotive (Frank, 2017, p. 312, Epstein, 1990). Thus, narratives offer more useful answers to complex, often disturbing and therefore challenging problems (O'Riordan, 2004)-like sustainability. Here, the narrative inquiry goes beyond a thematic analysis as "coding exercise," asking for what is represented in the data. Instead, in a narrative approach, the researcher takes the story as (eco)cultural identity building process and looks at the stories individuals create; the research aims at understanding how people are representing themselves, or their experiences, to themselves and to others and why. Thus, there is a greater amount of inductive reasoning and interpretation in narrative inquiries; the interviewees craft personal narratives that demonstrate meaning in their lives (Adler et al., 2017). Therefore, in the interviews we stimulated storytelling using Rory's Story Cubes ${ }^{\circledR}$ (see Figure 2), in addition to a questionnaire, which was used as a guideline to discover the interviewee's links to their biographical background. With this innovative tool (see Figure 2), we as researchers were able to interprete the sustainability-related everyday life-stories that are told within the context of research.

Applying the dice as picture-elicited storytelling approach, we started with compiling the stories ("Please tell me a story that you personally link to sustainability"). Concretely, the pictogram dice (Figure 2) were used as a visual stimulus, which was meant to aid interviewees to tell their sustainabilityrelated story-deconstructing the complexity of the issue itself (Crilly et al., 2006).

Overall, the interviews were divided into three distinctive sections, namely A: Story/Story Cubes, B: Biography and C: 


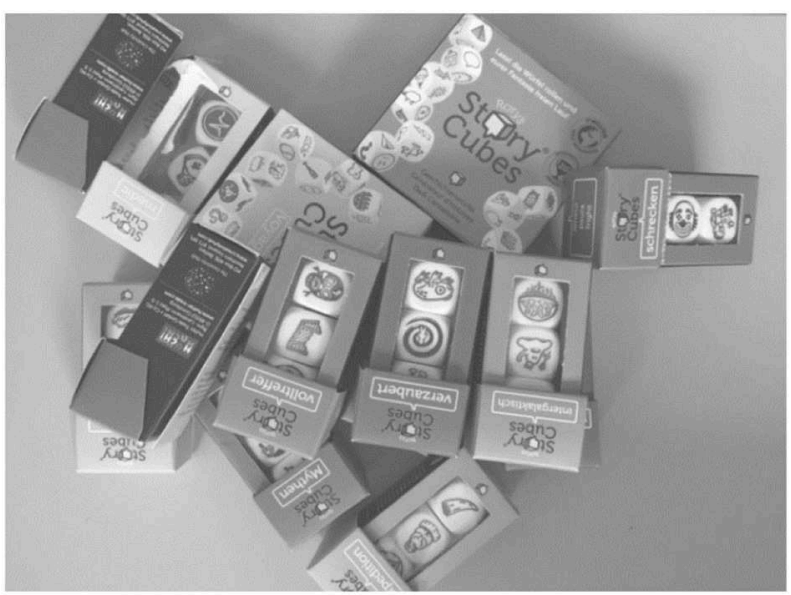

FIGURE 2 | Story cubes, dice with pictograms to stimulate storytelling.

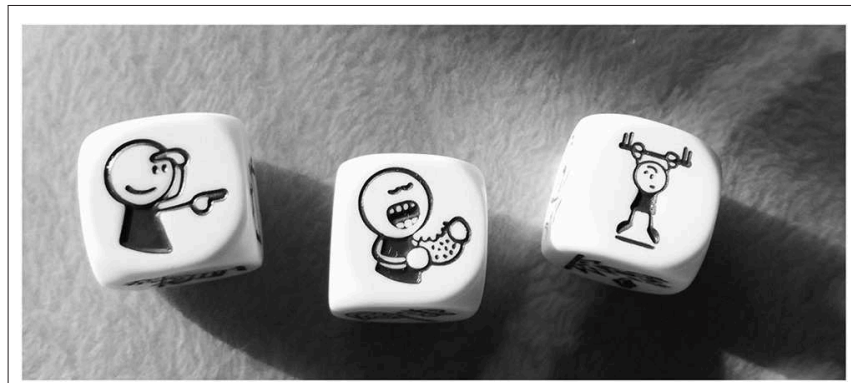

FIGURE 3 | Example of thrown dice.

Comments. We started the interviews with section A using the Story Cubes, because plots contain chains of actions and events. However, a minimal plot is sufficient to make sense of the narrative (Czarniawska, 1998, 2004). From the (even minimal) plot, we can go a step further into understanding the narrative, because the narrative is thematically organized by plots (Polkinghorne, 1988). Each participant was instructed to throw the dice and choose up to three dice which they could relate to a personal sustainability-related story. The dissonances as well as strategies of harmonization were possible to screen out with the use of Rory's Story Cubes ${ }^{\circledR}$, as the pictograms are random. The dice caught the interviewees off-guard because they had to tell a story which was related to the pictograms that they had rolled (see Figure 3).

The stories had to be an event they had experienced firsthand. Arranged blocks of stories in a unified theme could then be laid out as a plot (Yoon and Park, 2016, p. 75). In their story, the individuals attribute significance to their action and events according to their effect on the whole (Polkinghorne, 1988). Afterwards, if not already mentioned in their story, they were asked how they felt about the experience they had described, such as guilt or pride and right or wrong to understand the degree of normativity related to sustainability as moral framework in Heidegger's sense of a narrative as tool to explore what we do or do not wish to become (Heidegger, 1965). Thus, all the dialogues in the interview are under the umbrella of the narrative. The last question asked during part $\mathrm{A}$ is the "source" of those feelings, which leads to part B. To find out about each participant's autobiography, part B focused on their childhood and upbringing regarding sustainability. This is seen as part of the narrative method because it employs selfnarrated lived experiences in order to find meaning and roles in one's life. Narratives reconstruct the past and anticipate the future (McAdams and Bowman, 2001, p. 11). Subjects such as sustainability-related rules within their household, what their parents told them about the issue and aspects in their lives which touch upon sustainability issues were discussed. Lastly, part $\mathrm{C}$ asked the interviewees to provide comments regarding sustainability and issues relating to it.

The interviews were conducted by the three authors, who each had significant background knowledge of the topic, detailed interview training and practical experience as well as the prescribed interview guideline (Bryman, 2016). The interviews, which were partially conducted in German and partly in English, were transcribed in the original language; the results were translated into English. The recordings of the interviews were literally transcribed (Mayring, 2002) and analyzed with the described narrative approach with QCAmap (https://www. qcamap.org). Here, the focus was laid on the content of the story and the interpretations of and references to sustainability as normative framework; as well, the problematization and harmonization strategies were of interest for this paper.

Our sample consisted of 18 female and 17 male participants, ranging in age from 25 to 54 years (average age: 33.52 years), including people from 8 different nationalities (American, Australian, Austrian, English, German, Israeli, Japanese, Thai). The one-to-one interviews were conducted in a specific University seeting (participants of a lecture about sustainable development, 2018; Austrian, German, and English) and a deliberately non-University setting, meaning a random sample of individuals (Australian, Israeli, Japanese, Thai, Austrian \& German). Guideposts for the recruitment process were to get a variety of stories from various cultural and ethnic backgrounds as well as from different age groups with an equal number of female and male interview partners. The procedures for the interviews were laid out in writing and clearly explained to the interviewees before the interviews proceeded. The interviees were able to choose the location of the interview and were offered alterantives (classroom/public or private). The interviewees are not named because it is not essential for the pursuit of the research question; a permission for recording and publication of the notes was given.

\section{FINDINGS}

As the interviews were qualitative in nature, there was a vast amount of information within each interview. Although various themes such as source of each participant's sustainability knowledge and the extent of that knowledge emerged, only information which was relevant for answering the research 
questions (RQs), how individuals perceive sustainability, what aspects they problematize and how they deal with moral dissonance, was analyzed.

Topics which appeared frequently throughout every interview were the exploration of "right doings" - what should be doneand "wrong doings"-what should not be done, in other words, "sustainable behavior" and "unsustainable behavior." However, the core of the interviews was the interpretation of the stories that were told within the context of the research. In the stories, not the problematized issue itself but rather the process of problematization and the moral compass for the evaluation ("good" or "bad behavior") was of interest. For instance, the story of a 30 year old female interviewee from America (IV\#11), stimulated by the dice used as an example in Figure 3 (see again Figure 3), was the following:

\section{"I went to the store and I just took a bunch of plastic bags that I'm also going to do nothing with. I'm going to leave them next to my other nice cloth bags and just I keep getting more of them so, you know, we are not really great about that."}

The issue is plastic waste and plastic bags in general; however, of main interest was dissonance and feeling of "we are not great in collecting and using plastic bags" itself. However, in our interpretation of the stories we discovered that there is only a limited relationship between sustainability and personal experiences; much more, sustainability is something that is represented by others, by family members (grandmother, parents), by friends ("there is this vegan friend of mine") or that is represented in the culture (old culture, like Thai; younger European movements, like Friday-for-future in Austria or Germany).

Thus, when speaking of sustainable behavior, more often than not, the participants related their actions not to sustainability directly but rather to "what people should do," in other words, a specific "lifestyle." For instance, a participant (IV\#6: Male, $36 y$., Japan) who compared his tendency to turn off household electronics before leaving the house to something as normal and necessary as paying attention to his clothing and appearance. $\mathrm{He}$ described this by saying

\footnotetext{
"... when I leave the house and I forgot to turn off my light. I just go back to my room and turn off the light or air conditioning and go out again... we feel like it's the same feeling, like, when you wear different kinds of socks. You feel like something strange. So, you want to- ... Yeah, correct it."
}

For this particular interviewee, following this "sustainable behavior" is embedded into his daily routine, just as much as putting on clothes is. Therefore, it could be concluded that it is already a part of his lifestyle. An unsustainable behavior feels unnatural to him, which leads to an inner necessity to correct his own actions. On the other hand, when speaking about "unsustainable behaviors," the participants linked this to their own or to others' "bad lifestyle" choices. These "bad lifestyles" were frequently followed by justifications of why they think these "bad behaviors" continue to happen. The justifications given by the participants recurrently paired with reasoning which accommodates or creates convenience for their existing lifestyle. An example of this could be found in the same interview, where the participant stated,

\footnotetext{
"We had to go to driving school. So, we often hear that stop idling, idling. Idling, which is- sometimes we're just waiting (for) someone in the car and you use air conditioning. But if you turn it off, you can see how much it could save the gas or CO2 (emission)."
}

The participant showed his knowledge regarding the connection between car exhaust and $\mathrm{CO}^{2}$ emission; nevertheless, he still justified his "unsustainable behavior" through this small gesture to accommodate his convenience for commuting or traveling by idling. Although, conducting idling is better than not to do so, it could not be denied that driving cars is still not the most sustainable method to commute. The participant justified his actions through this small gesture to accommodate his convenience for commuting or traveling.

Applying the theoretical thoughts, the conceptualized harmonization strategies could be found in various stories, i.e., IV\#23, male German, aged 40, said,

\begin{abstract}
"I guess the main thing was turning off lights and electricity and water. But, I guess, water was more sustainability. It's, like, things adults tell kids "don't waste water because you may not have them anymore etc." but electricity, it was more about the financial-sort of trying to save cost, more than anything. But water, definitely, was something that had always been-we've always been told "turn off water when you brush your teeth," "turn off water when you're using soap," or-basically, don't waste water. It's always been-even at school as well, growing up, you know, that was something that was heavily discussed at school."
\end{abstract}

The participant had knowledge about what he believes is sustainable behavior, where the norm is institutionalized (like schools). He had learned from school and the emerging discourse between him and his friends, although he is not certain why they had to tell him. And he did remember those sustainable behavior guidelines-but felt his inability to cope with it completely-and blaming the institution/the system for it:

"Actually, I think, they never explained to me why we should do it.
Yeah, they told me to do it. They would explain just briefly, like,
"if you waste water, in the end we would not have any water left" or
something like that. But they weren't really advocating for recycling,
for example, or anything like that. That's something more that I sort
of picked up as I grew up. Well, I mean at school, I think aside from
school rules, that had notices placed in toilets, where it says "don't
waste water" and things like that.... But I just felt like there were
more room for me to slack off with it."

In this case, the participant used moral corruption to justify not behaving sustainably. In saying that when you live in a country that has no water scarcity to experience and, related to that, no "official rule" or regulation, it became a "social norm" to "slack off" on the sustainable behavior. The participant justified his unsustainable behavior by seeing it as less strict and changing the 
morality, in this case through "social norm," of his behavior to coincide with his actions.

Another interviewee (IV\#9, Japanese, female, aged 34) said,

\begin{abstract}
"Okay. Let me talk about my background. I'm from Japan and so as my company's reputation we-Our company have to be efficient for everything. So, for example, the reason why I choose this... Cube. (is) Because I remember that when I was a little, in Japan, we have four seasons. So, summer time is very hot, the winter time very cold. So, we rely on the air conditioning and also heater. When we were little, we didn't think of anything, right? So, when you go to 7-11, like one hour you're away, I just-I wanted to keep my room cold. Because when I came back from 7 to 11, I don't want to wait until the room is getting cooler. So, I put the air con on."
\end{abstract}

The interview participant used external factors, in this case the fact that the weather is changing and challenging, to problematize and justify the use of air conditioners. This is an example of moral dissonance that he was able to eliminate guilt through an external justification. Additionally, in the same interview, reflections on plastic bags used for "big shopping" were justified in a different way, here with flawed logic i.e., using the plastic bags to create balloons or other handcraft activities, to accommodate the behavior evaluated as unsustainable.

As conceptualized in the theoretical section, individuals involve themselves in an issue by problematizing it in relation to sustainability as normative framework. In other words, without a problematization of an issue with sustainability as normative reference point or moral compass (Weder et al., 2019a), there will be no engagement in finding a solution followed by sustainable practices.

\section{COGNITIVE FRICTION}

At this point, we derive from the interview data that various harmonization strategies are used-however, a certain cognitive friction remains when individuals think about and evaluate the degree of sustainability of their behavior (see Figure 4). Much more, sustainability itself as a normative framework apparently

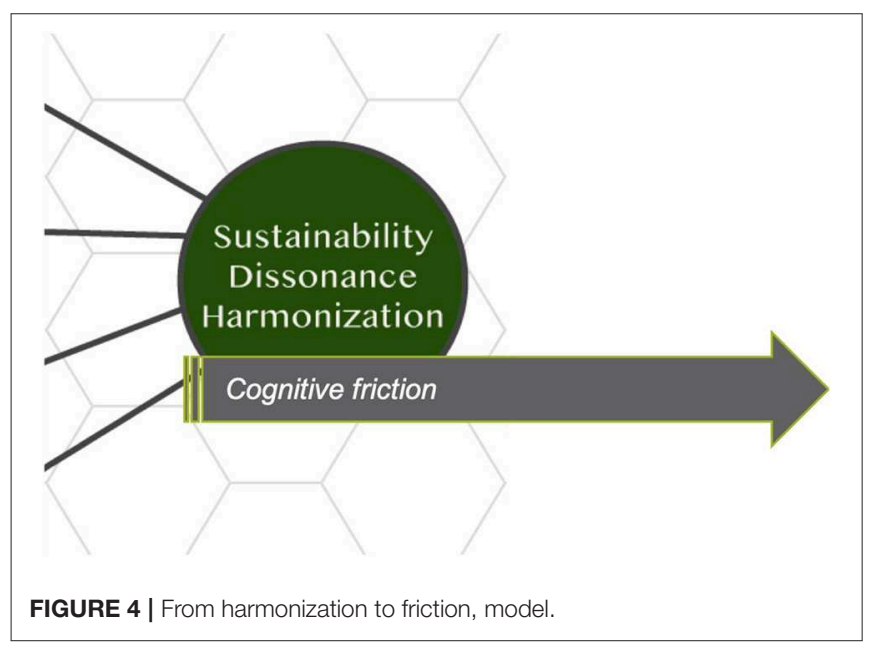

functions as constant cognitive friction for individual behavior today-reflected by relating their personal experience with their culture, external factors like climatic conditions and behavior of others (family, friends).

Even the individuals, that perceive the notion of sustainability as a certain lifestyle, feel a cognitive friction in their individual action because the lifestyle is never perceived as "fully sustainable" in the sense of "good." Instead of a cognitive diversity, most of the interviewees mentioned the "friction" in the same way, as something that gives them a constant feeling of not doing "enough," not coping as good as they could with climate change related problems, like the following ( $I V \# 17$, female, aged 25, from Austria):

\footnotetext{
"It's never enough, I feel helpless... I can't even blame any institution, or politicians or "the system," I just feel that it's never enough that I do, just insufficient."
}

Here, in addition to the theoretical framework presented above, we draw on Sweller (1988) who discussed the idea of cognitive friction in his work, describing the mental effort that is used in the working memory. Due to the fact, that the storytelling was focused on a story that happened to the interviewed person (happened in the past), this friction could be detected. Sweller further mentions the interplay between the sensory memory, receiving the information from your daily actions and activities. The sensory information passes into the working memory which either processes it or discards it. Here, we can see the link to harmonization strategies, mainly Festinger's concept of cognitive dissonance. Furthermore, the individual processes the information and tries to categorize it. It is a process of learning and putting the experience or action into a specific knowledge structure or scheme. Then it passes into long-term memory. Generally, a heavy cognitive load can lead to errors and interference-which is described as friction. In 1999, Alan Cooper described the concept of cognitive friction as individuals' perception of high-tech gadgetry, as "the resistance encountered by human intellect when it engages with a complex system of rules that change as the problem permutes," recommending "clear paths" to meet this friction. Thus, with our study, we can show that sustainability works less as moral framework for individual behavior; much more, it gives a pathway toward helping people to judge behavior as "morally good" (sustainable) or "bad" (unsustainable). However, there are always harmonization strategies that soften the framework. The interviews provided confidence in the SDH model, because when justifications regarding unsustainable behaviors were discussed, participants often offered justification in order to accommodate convenience in their lifestyle. However, after listening to and analyzing the stories and relating the stories to the individuals background, we had to refine our concept in the following terms: Sustainability is a normative framework on a societal, institutionalized level, however on an individual level sustainability works as cognitive friction that remains even after harmonization strategies have been applied to dissonances. 


\section{DISCUSSION}

As proposed in the theoretical section, this research mainly aimed at learning about the degree of normativity in sustainability communication and how this resonates with individuals on a personal level. In other words, we wanted to explore how individuals perceive sustainability from all of the sustainabilityrelated communication which they were exposed to and how much they relate the issue of sustainability to their personal experiences. Here, with a narrative approach, our close attention was paid less to the issues that were brought up but rather to the process of problematization, represented in cognitive dissonances that we could find in this problematization process of a certain (un)sustainable behavior or practice. With our innovative storytelling approach we were able to trace back individual evaluations of a certain behavior as sustainable-or not-with sustainability as a more or less institutionalized normative framework. Even with harmonization strategies to cope with incongruent values, individual considerations and sense-making processes, dissonances remain because sustainability is still seen as "heavy cognitive load" that leads to errors and interference which we describe as cognitive friction.

The value of the study and mainly the application of a very specific, innovative storytelling method is our ability to bridge the gap between individual behavior and a multitude of mostly incongruent values and considerations and, by the same time, capturing the process of reflection on dissonances and strategies to cope with a remaining "cognitive friction."

The method enabled participants to forge a connection between the subject and their personal experiences, it works as an effective vehicle to exert underlying themes and offer an insight into personal beliefs. It could not be denied that storytelling plays an important role in human communication. Atkinson (1998, p. 2) said that "storytelling is a fundamental form of human communication. It can serve as an essential function in our lives. We often think in story form, speak in story form ...". The author also said that when individuals retell a story of their experience, it provides them with a deeper understanding of their experience because they had to reflect upon what had happened. This leads to one of the most interesting secondary outputs of this research, the use of Rory's Story Cubes ${ }^{\circledR}$. To get a direct access to people's interpretations, associations and understanding of sustainability, we used the dice to stimulate stories about sustainability-related life events. With our study, it was proven to be not only a good conversational starter with the interviewees. Much more, the stories that were told, stimulated by the dice, leading to the conclusion that personal experiences related to sustainability as framework are always related to a specific cultural background as well as behavior in the social context, meaning the network of family, colleagues, and friends. Thus, sustainable behavior is socially constructed as it is the moral compass for the problematization and evaluation of individual behavior.

As mentioned in the beginning of this paper, the notion of sustainability comes with a great deal of complexity. When we mentioned the topic to our interviewees, more often than not, they tensed up and showed signs of uneasiness. However, the cubes themselves were originally designed to function as a board game. Therefore, using them in the interviews added aspects of fun and informality to a complex topic of interest. We found that participants eased up and had proneness to engage through the use of the dice.

Even though most of the participants seemed to be stimulated positively by the Story Cubes, it has to be acknowledged as another limitation of the study that there is the possibility that interviewees may end up pursuing their own agendas, telling preformulated stories, rather than engaging with the interviewer, and getting into the process of narrative storytelling. Furthermore, picture-elicited research methods in general require considerable attention to concerns of power and representation on the part of the interviewers and the research team in the background (Weder et al., 2019a).

However, with our specific approach of stimulating a story with the Story Cubes to detect problematization as a core process of storytelling in general we complement existing storytelling approaches. The use of visual stimuli can enhance these memories and provoke a higher level of participant-led involvement; it can be seen as a fruitful supplement to explore a wider range of emotions, memories and stories. Thus, the "restorying" approach using Story Cubes as a research method as well as framework for the analysis has the potential to enhance a deeper understanding of individual perceptions of sustainability and cognitive friction, that, again, challenges organizational, corporate as well as political communication and hinders a social transformation in the sense of a sustainable development.

Overall, the innovative method offered a substantive and theoretical contribution through the analysis and interpretation of the social as well as individual construction of sustainability and also new insights into how sustainability works not only as normative framework for individual behavior but much more as moral compass producing cognitive friction. The collected sustainability stories show that the feeling of "never doing enough" is either a motivation for "better" or at least changed behavior. In some cases it was used as a justification for not doing more or even giving up in the sense of seeing sustainable behavior as a fruitless task which is not even worth trying. This has implications for all forms of strategic communication of, about and for sustainability that can be further considered in the fields of Organizational Communication, Public Relations, Strategic Sustainability Communication, and Science Communication as well as CSR Communication. Furthermore, it challenges a one-directional, functional perspective on communication as information. It invites critical and cultural studies to learn more about multiple channels that are needed to create contexts which are more conductive to the facilitation of sustainable choices. Last but not least, the here presented methodological approach as well as the learnings about cognitive friction that emerges with sustainability as normative framework for individual behavior stimulate further research from a psychological as well as communication perspective. Much more research on the relationship between social representations of sustainability in the media, in advertisement, in political and other forms of corporate and organizational communication and framing of individual behavior and related cognitive processes is needed. 
Based on that, the potential of sustainability communication influencing behavior changes and societal transformation processes can be studied in the future.

\section{DATA AVAILABILITY STATEMENT}

The datasets generated for this study are available on request to the corresponding author.

\section{ETHICS STATEMENT}

The studies involving human participants were reviewed and approved by Ethic committee at the Department of Media

\section{REFERENCES}

Adler, J. M., Dunlop, W. L., Fivush, R., Lilgendahl, J. P., Lodi-Smith, J., McAdams, D. P., et al. (2017). Research methods for studying narrative identity: a primer. Soc. Psychol. Pers. Sci. 8, 519-527. doi: 10.1177/1948550617698202

Allen, M. (2016). Strategic Communication for Sustainable Organizations: Theory and Practice. Cham: Springer. doi: 10.1007/978-3-319-18005-2

Aristotle (1996). Poetics. Transl. by M. Heath in Portuguese. London: Penguin Books.

Aronson, E. (1969). The theory of coginitive dissonance: a current perspective1. Adv. Exp. Soc. Psychol. 4, 1-34. doi: 10.1016/S0065-2601(08)60075-1

Atkinson, R. (1998). The Life Story Interview. Thousand Oaks, CA: Sage Publications. doi: 10.4135/9781412986205

Bäckstrand, K. (2003). Civic science for sustainability: reframing the role of experts, policymakers and citizens in environmental governance. Glob. Environ. Polit. 3, 24-40. doi: 10.1162/152638003322757916

Bal, M. (1997). Narratology: Introduction to the Theory of Narrative. Toronto, ON: University of Toronto Press.

Bem, D. (1967). Self-perception: an alternative interpretation of cognitive dissonance phenomena. Psychol. Rev. 74, 183-200. doi: 10.1037/h0024835

Bilharz, M., and Schmitt, K. (2011). Going big with big matters. The key point approach to sustainable consumption. GAIA 20, 232-235. doi: 10.14512/gaia.20.4.5

Bjorn, A., Richardson, K., and Hauschuild, M. Z. (2019). Framework for development and communication of absolute environmental sustainability assessment methods. J. Ind. Ecol. 23, 838-854. doi: 10.1111/jiec.12820

Blanken, I., van de Ven, N., and Zeelenberg, M. (2015). A meta-analytic review of moral licensing. Pers. Soc. Psychol. Bull. 41, 540-558. doi: $10.1177 / 0146167215572134$

Brackin, P., House, R., Mueller-Price, J., DeVasher, M., Layton, R. A., Taylor, C., et al. (2011). Institutionalized: organizational obstacles to communicating sustainability. IEEE Int. Prof. Commun. Conf. 39, 1-5. doi: 10.1109/IPCC.2011.6087214

Braun, V., and Clarke, V. (2006). Using thematic analysis in psychology. Qual. Res. Psychol. 3, 77-101. doi: 10.1191/1478088706qp063oa

Bryman, A. (2016). Social Research Methods, 5th Edn. Oxford: Oxford University Press.

Charmaz, K. (2014). Constructing Grounded Theory. 2nd Edn. London: Sage.

Chaudhuri, A., and Jayarem, J. (2018). A socio-technical view of performance impact of integrated quality and sustainability strategies. Int. J. Prod. Res. 57, 1478-1496. doi: 10.1080/00207543.2018.1492162

Crable, R. E., and Vibbert, S. L. (1985). Managing issues and influencing public policy. Public Relat. Rev. 11, 3-15. doi: 10.1016/S0363-8111(82)80114-8

Crilly, N., Blackwell, A., and Clarkson, P. (2006). Graphic elicitation: using research diagrams as interview stimuli. Qual. Res. 6, 341-366. doi: $10.1177 / 1468794106065007$

Crotty, M. J. (1998). Foundations of Social Research: Meaning and Perspective in the Research Process. London: SAGE Publications. and Communication, contact: FW. The patients/participants provided their written informed consent to participate in this study.

\section{AUTHOR CONTRIBUTIONS}

SL was a specialist for empirical research and qualitative methodologies. AT was responsible for the coordination of the interviews. FW was in the lead of the project re-storying sustainability and a guide for the co-authors due to her background in sustainability communication, organizational communication, and environmental communication research. All authors worked for the paper with their specific input.

Czarniawska, B. (1998). A Narrative Approach to Organization Studies. London: Sage. doi: 10.4135/9781412983235

Czarniawska, B. (2004). Narratives in Social Research: Introducing Qualitative Methods. Thousand Oaks, CA: Sage.

Dade, A., and Hassenzahl, D. (2013). Communicating sustainability: a content analysis of website communications in the United States. Int. J. Sustain. High. Educ. 14, 254-263. doi: 10.1108/IJSHE-08-2011-0053

Dahlstrom, M. F. (2014). Using narratives and storytelling to communicate science with nonexpert audiences. Proc. Natl. Acad. Sci. U.S.A. 111(Suppl. 4), 13614-13620. doi: 10.1073/pnas.1320645111

Dahlstrom, M. F., and Ho, S. S. (2012). Ethical considerations of using narrative to communicate science. Sci. Commun. 34, 592-617. doi: $10.1177 / 1075547012454597$

Daily, B. F., and Huang, S. C. (2001). Achieving sustainability through attention to human resource factors in environmental management. Int. J. Oper. Prod. Manag. 21, 539-1552. doi: 10.1108/01443570110410892

De Graaf, A., Sanders, J., and Hoeken, H. (2016). Characteristics of narrative interventions and health effects: a review of the content, form and context of narratives in health-related narrative persuasion research. Rev. Commun. Res. 4, 88-131. doi: 10.12840/issn.2255-4165.2016.04.01.011

Diehl, S., Karmasin, M., Mueller, B., Terlutter, R., and Weder, F. (eds.) (2017). Handbook of Integrated CSR Communication. Cham: Springer. doi: 10.1007/978-3-319-44700-1

Djordjevic, A., and Cotton, D. R. E. (2011). Communicating the sustainability message in higher education institutions education for sustainability project. Int. J. Sustain. High. Educ. 12, 381-394. doi: 10.1108/14676371111168296

du Gay, P., Hall, S., Janes, L., Mackay, H., and Negus, K. (1997). Doing Cultural Studies: The Story of the Sony Walkman. London: SAGE Publications.

Dunlap, R. E. (2013). Climate change skepticism and denial: an introduction. Am. Behav. Sci. 57, 691-698. doi: 10.1177/0002764213477097

Eckstein, B. (2003). "Making space: stories in the practice of planning," in Story and Sustainability, eds B. Eckstein and J. Throgmorton (Cambridge, MA: MIT Press), 13-31. doi: 10.7551/mitpress/6472.001.0001

Edmunds, A., and Morris, A. (2000). The problem of information overload in business organisations: a review of the literature. Int. J. Inf. Manag. 20, 17-28. doi: 10.1016/S0268-4012(99)00051-1

Elving, W., Golob, U., Podnar, K.,Ellerup-Nielsen, A., and Thomson, C. (2015). Guest editorial: the bad, the ugly and the good: new challenges for CSRcommunication. Corp. Commun. Int. J. 20, 118-127. doi: 10.1108/CCIJ-02-2015-0006

Epstein, S. (1990). "Cognitive experiental self-theory," in Handbook of Personality: Theory and Research, ed L. Pervin (New York, NY: Guilford Press), 165-192.

Festinger, L. (1962). A Theory of Cognitive Dissonance. Stanford, CA: Stanford University Press. doi: 10.1038/scientificamerican1062-93

Fischer, D., Haucke, F., and Sundermann, A. (2017). What does the media mean by 'sustainability' or 'sustainable development'? An empirical analysis of sustainability terminology in German newspapers over two decades. Sustain. Dev. 25, 610-624. doi: 10.1002/sd.1681 
Frank, A. K. (2017). What is the story with sustainability? A narrative analysis of diverse and contested understandings. J. Environ. Stud. Sci. 7, 310-323. doi: 10.1007/s13412-016-0388-3

Gardiner, S. (2013). A Perfect Moral Storm: The Ethical Tragedy of Climate Change. New York, NY: Oxford University Press. 301-309.

Gass, W. (2002). Tests of Time. New York, NY: Alfred Knopf.

Genc, R. (2017). The importance of communication in sustainability \& sustainable strategies. Procedia Manuf. 8, 511-516. doi: 10.1016/j.promfg.2017. 02.065

Giovannoni, E., and Fabietti, G. (2013). "What is sustainability? A review of the concept and of its applications," in Integrated Reporting: Concepts and Cases That Redefine Corporate Accountability (Springer), 21-40.

Godemann, J., and Michelsen, G. (2011). Sustainability Communication. Interdisciplinary perspectives and Theoretical Foundations. Dordrecht: Springer. doi: 10.1007/978-94-007-1697-1

Golob, U., Verk, N., Ellerup-Nielsen, A., Thomsen, C., Elving, W. J., and Podnar, K. (2017). The communicative stance of CSR: reflections on the value of CSR communication. Corp. Commun. Int. J. 22, 166-177. doi: 10.1108/CCIJ-03-2017-0019

Hall, S. (1997). Representation: Cultural Representations and Signifying Practices. London: Sage.

Harmon-Jones, E., and Harmon-Jones, C. (2007). Cognitive dissonance theory after 50 years of development. Zeitschrift Für Sozialpsychologie 38, 7-16. doi: 10.1024/0044-3514.38.1.7

Heidegger, M. (1965). Being and Truth. New Haven, CT: Yale University Press.

Herrick, C. N., and Pratt, J. L. (2013). Communication and the narrative basis of sustainability: observations from the municipal water sector. Sustainability 5 , 4428-4443. doi: 10.3390/su5104428

Hinyard, L. J., and Kreuter, M. W. (2007). Using narrative communication as a tool for health behaviour change: a conceptual, theoretical, and empirical overview. Health Educ. Behav. 34, 777-792. doi: 10.1177/1090198106 291963

Hoppe, I., and Wolling, J. (2017). "Nachhaltigkeitskommunikation," in Forschungsfeld Wissenschaftskommunikation, eds H. Bonfadelli, B. Fähnrich, C. Lüthje, J. Milde, M. Rhomberg, and M. S. Schäfer (Wiesbaden: Springer Fachmedien Wiesbaden), 339-354. doi: 10.1007/978-3-658-1289 8-2_18

Huang, L., Clarke, A., Heldsinger, N., and Tian, W., (2019). The communication role of social media in social marketing: a study of the community sustainability knowledge dissemination on LinkedIn and Twitter. J. Market. Anal. 7, 64-75. doi: 10.1057/s41270-019-00053-8

Johnston, P., Everard, M., Santillo, D., and Robèrt, K. H. (2007). Reclaiming the definition of sustainability. Environ. Sci. Pollut. Res. Int. 14, 60-66. doi: 10.1065/espr2007.01.375

King, D. (2013). It's Time to Ban the Empty Word 'Sustainability'. The Conversation. Available online at: http://theconversation.com/its-time-toban-the-empty-word-sustainability-17612 (accessed November 20, 2019).

Knauff, M., and Wolf, A. (2010). Complex cognition: the science of human reasoning, problem-solving, and decision-making. Cogn. Process. 11, 99-102. doi: 10.1007/s10339-010-0362-z.

Kuntsman, A., and Rattle, I. (2019). Towards a paradigmatic shift in sustainability studies: a systematic review of peer reviewed literature and future agenda setting to consider environmental (Un)sustainability of digital communication. Environ. Commun. 13, 567-581. doi: 10.1080/17524032.2019. 1596144

Laszlo, J. (1997). "Narrative organization of social representations," Papers on Social Representations, 6, 155-172.

László, J. (2008). The Science of Stories: An Introduction to Narrative Psychology. Routledge: Taylor \& Francis. Group.

Lever-Tracy, C. (ed.) (2010). Routledge Handbook of Climate Change and Society. New York, NY: Routledge. doi: 10.4324/9780203876213

Linea, N. D., Hanksb, L., and Zhangc, L. (2016): Sustainability communication: the effect of message construals on consumers' attitudes towards green restaurants. Int. J. Hosp. Manag. 57, 143-151. doi: 10.1016/j.ijhm.2016. 07.001

Lowell, J. (2012). Managers and moral dissonance: self justification as a big threat to ethical management? J. Bus. Ethics 105, 17-25. doi: 10.1007/s10551-011-0931-9
Lyotard, J. (1984). "The postmodern condition," in A Report on Knowledge, eds G. Bennington and B. Massumi (Minneapolis, MN: University of Minnesota Press). doi: 10.2307/1772278

Maltseva, K., Fieseler, C., and Trittin-Ulbrich, H. (2019). The challenges of gamifying CSR communication. Corp. Commun. Int. J. 24, 44-62. doi: 10.1108/CCIJ-09-2018-0092

Marshall, J., and Toffel, M. (2005). Framing the elusive concept of sustainability: a sustainability hierarchy. Environ. Sci Technol. 39, 673-682. doi: 10.1021/es040394k

Mayring, P. (2002). "Qualitative content analysis: research instrument or mode of interpretation?, in The Role of the Researcher in Qualitative Psychology, ed M. Kiegelmann (Tübingen: Ingeborg Huber), 139-148.

McAdams, D. P., and Bowman, P. J. (2001). "Narrating life's turning points: redemption and contamination," in Turns in the Road: Narrative Studies of Lives in Transition, eds D. P. McAdams, R. Josselson, and A. Lieblich (Washington, DC: American Psychological Association), 3-34. doi: 10.1037/104 10-001

McKenzie, S. (2004). Social Sustainability: Towards Some Definitions. Magill, SA: Hawke Research Institute; University of South Australia.

Merritt, A. C., Effron, D. A., and Monin, B. (2010). Moral self- licensing: when being good frees us to be bad. Soc. Pers. Psychol. Compass 4, 344-357. doi: 10.1111/j.1751-9004.2010.00263.x

Miller, J. (1995). "Narrative," in Critical Terms for Literature Study, eds F. Lentricchia and T. McLaughlin (Chicago, IL: University of Chicago Press), 66-79.

Newig, J., Schulz, D., Fischer, D., Hetze, K., Laws, N., Lüdecke, G., et al. (2013). Communication regarding sustainability: conceptual perspectives and exploration of societal subsystems. Sustainability 5, 2976-2990. doi: $10.3390 /$ su5072976

Norgaard, K. M. (2011). Living in Denial. Climate Change, Emotions, and Everyday Life. Cambridge; London: MIT Press. doi: 10.7551/mitpress/9780262015448.001.0001

O’Riordan, T. (2004). Environmental science, sustainability and politics. Trans. Inst. Br. Geogr. 29, 234-247. doi: 10.1111/j.0020-2754.2004.00127.x

Ott, K., Muraca, B., and Baatz, C. (2011). "Strong sustainability as a frame for sustainability communication," in Sustainability Communication. Interdisciplinary Perspectives and Theoretical Foundations, eds J. Godemann and G. Michelsen (Dordrecht: Springer), 13-26. doi: 10.1007/978-94-007-1697-1_2

Polkinghorne, D. (1988). Narrative Knowing and the Human Sciences. Albany, NY: State University of New York Press.

Rasche, A., Morsing, M., and Moon, J. (2017). Corporate Social Responsibility. Strategy, Communication, Governance. Cambridge: Cambridge University Press. doi: 10.1017/9781316335529

Sandercock, L. (2003). "The power of story in planning" in Cosmopolis II: Mongrel Cities of the 21st Century, ed L. Sandercock (New York, NY: Continuum), 181-203.

Smith, J. A., Flower, P., and Larkin, M. (2009). Interpretative phenomenological analysis: theory, method and research. Qual. Res. Psychol. 6, 346-347. doi: 10.1080/14780880903340091

Sprain, L., and Timpson, W. M. (2012). Pedagogy for sustainability science: case-based approaches for interdisciplinary instruction. Environ. Commun. 6, 532-550. doi: 10.1080/17524032.2012.714394

Stecula, D. A., and Merkley, E. (2019). Framing climate change: economics, ideology, and uncertainty in American news media content from 1988 to 2014. Front. Commun. 4:6. doi: 10.3389/fcomm.2019.00006

Steele, C. M. (1988). "The psychology of self-affirmation: sustaining the integrity of the self," in Advances in Experimental Social Psychology, ed L. Berkowitz (San Diego, CA: Academic Press), 261-302. doi: 10.1016/S0065-2601(08)6 0229-4

Stern, P. (2005). Deliberative methods for understanding environmental systems. BioScience 55, 976-982. doi: 10.1641/0006-3568(2005)055[0976:DMFUES]2.0. $\mathrm{CO} ; 2$

Stibbe, A. (2015). Ecolinguistics: Language, Ecology and the Stories we Live by. London: Routledge.

Sweller, J. (1988). Cognitive load during problem solving: effects on learning. Cogn. Sci. 12, 257-285. doi: 10.1207/s15516709 $\operatorname{cog} 1202 \_4$ 
Taylor, J. R., and Van Every, E. J. (2000): The Emergent Organization. Communication as its Site and Surface. Mahwah, NJ: Lawrence Erlbaum. doi: 10.4324/9781410602275

United Nations (2018). Sustainable Development Goals. Knowledge Platform. Available online at: https://sustainabledevelopment.un.org/?menu=1300 (accessed November 20, 2019).

van Dam-Mieras, R., Lansu, A., Rieckmann, M., and Michelsen, G. (2008). Development of an interdisciplinary, intercultural master's program on sustainability: learning from the richness of diversity. Innov. High. Educ. 32, 251-264. doi: 10.1007/s10755-007-9055-7

Weder, F. (2017). "CSR as common sense issue," in Handbook of Integrated CSR Communication, eds S. Diehl, M. Karmasin, B. Mueller, R. Terlutter, and F. Weder (Berlin: Springer), 23-36. doi: 10.1007/978-3-319-44700-1_2

Weder, F., Einwiller, S., and Eberwein, T. (2019c). Heading for new shores. Impact orientation of CSR communication and the need for communicative responsibility. Corp. Commun. Int. J. 24, 198-211. doi: 10.1108/CCIJ-02-2019-0020

Weder, F., Karmasin, M., and Krainer, L. (2019b). The Sustainability Communication Reader. A Reflective Compendium. Dordrecht: Springer.

Weder, F., and Krainer, L. (2011). Editorial. Medienjournal 1/2011: Nachhaltigkeitskommunikation, S. 2-3. Google Scholar.

Weder, F., Lemke, S., and Tungarat, A. (2019a). (Re)storying Sustainability: the use of story cubes in narrative inquiries to understand individual perceptions of sustainability. Sustainability 11:5264. doi: 10.3390/su11195264
Weick, K. E. (1979). The Social Psychology of Organizing, 2nd Edn. New York, NY: McGraw-Hill.

Woods, J. (2010). We All Know Fast Food is Bad for Us [online]. Telegraph.co.uk. Available online at: https://www.telegraph.co.uk/news/health/7847471/We-allknow-fast-food-is-bad-for-us.html (accessed October 25, 2018).

Yoon, G., and Park, A. M. (2016). Narrative identity negotiation between cultures: storytelling by Korean Immigrant Career Women. Asian J. Women's Stud. 18, 68-97. doi: 10.1080/12259276.2012.11666132

Ziegler, R., Schulz, S., Richter, L., and Schreck, M. (2014). Follow Ghandi: social entrepreneurship as a non-violent way of communicating sustainablity challenges. Sustainability 6, 1018-1036. doi: 10.3390/su60 21018

Conflict of Interest: The authors declare that the research was conducted in the absence of any commercial or financial relationships that could be construed as a potential conflict of interest.

Copyright (c) 2020 Weder, Tungarat and Lemke. This is an open-access article distributed under the terms of the Creative Commons Attribution License (CC BY). The use, distribution or reproduction in other forums is permitted, provided the original author(s) and the copyright owner(s) are credited and that the original publication in this journal is cited, in accordance with accepted academic practice. No use, distribution or reproduction is permitted which does not comply with these terms. 